\title{
Rock burst mechanics as a time dependent event
}

\author{
J. Vacek \& S. Hrachová-Sedláčková \\ Klokner Institute, \\ Czech Technical University in Praha, Czech Republic
}

\begin{abstract}
This paper deals with the behaviour of open rock that occurs, for example, during long wall mining in coal mines, in deep tunnel, or shaft excavation. Long wall instability leads to extrusion of rock mass into an open space. This effect is mostly referred to as a bump, or a rock burst. For bumps to occur, the rock has to possess certain particular rock burst properties leading to accumulation of energy and the potential to release this energy. Such materials may be brittle, or the bumps may arise at the interfacial zones of two parts of the rock, which have principally different material properties. The solution is based on experimental and mathematical modelling. These two methods have to allow the problem to be studied on the basis of three presumptions:

- the solution must be time dependent

- the solution must allow the creation of crack in the rock mass

- the solution must allow an extrusion of rock into an open space (bump effect)
\end{abstract}

A part of the presentation will be bump video from mathematical and experimental tests.

Keywords: rock burst, bump, mining, rock mechanics, mathematical and physical modelling.

\section{Introduction}

The bump is the most dangerous event that can occur during excavation works. The surrounding rock is extruded into underground open space by severe force during a bump. This event may cause injury or even death to mining workers and it may be the cause of the destruction of the excavation space. This is the reason 
why the study of this problem is very important for theory and praxis (see [1-3, 7]).

Sufficient high pressure in the bump place is necessary for bump occurrence (usually great depth, but also tectonic pressure) and rock must be brittle and must have the disposition for a bump (properties that allow creation of bumps).

For the occurrence of bursts, mining velocity is also very important. In the same condition, when we excavate slowly, we give rock mass sufficient time to create cracks in the open space vicinity. This is the reason why stress concentration next to an excavation falls down, and a bump does not occur. If mining works proceed rapidly, the crack has no time to occur, and a bump appears. This feature is confirmed by old mining experience. This is also the reason why it is necessary to study this event as a time dependent problem.

A bump was studied for the case of a mine gallery inside a horizontal coal seam. Its mechanics and stress distribution on the top of seam was studied by mathematical and experimental modelling.

\section{Experimental part}

\subsection{Testing devices}

\subsubsection{Loading cell}

Fig. 1 shows the loading cell. It consists of a lower steel tank, which is designed for the horizontal forces caused by vertical load in araldite specimens. The loading cell is equipped with lucites on its sides, which allow observation of samples during the tests. The tank is shown in Figure 5. This loading cell models (simulates) the rock mass in the vicinity of the seam. We placed two araldite specimens in the loading cell (with dimensions of 160/400/70 mm), which model the coal seam. The gap between them corresponds to the width of a working gallery in a mine. We observed the mechanism and the history of coal bumps. The araldite specimen was covered with a soft duralumin sheet, and a force of meters were placed on it in the following manner: five comparatively thick force meters were placed near to its outer edge and another 15 thinner force meters were placed next to them, (see Figure 1 and Figure 5). In order to embed the

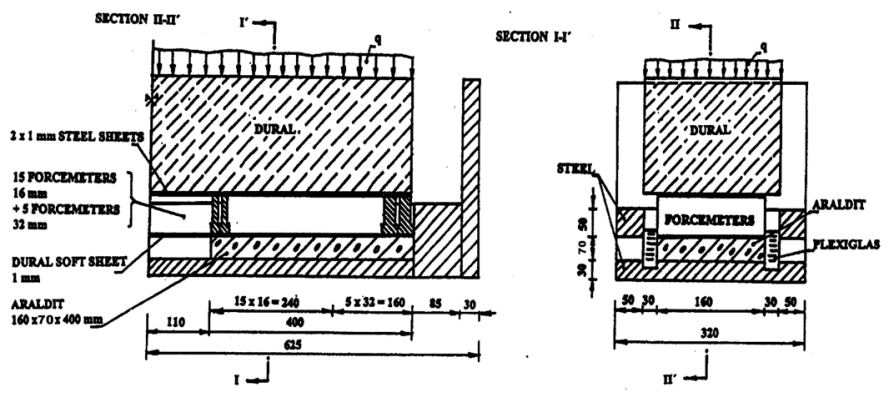

Figure 1: $\quad$ Scheme of loading cell. 
force meters properly and to prevent them from tilting, another double steel sheet, $1 \mathrm{~mm}$ thick, was placed over the force meters. A block of duralumin with the height of $300 \mathrm{~mm}$ was placed over this sheet. This block simulates the handing wall and models stress distribution similar to that in reality (see Figure 2).

\subsubsection{Force meters}

Figure 5 shows the force meters. The force meters are $160 \mathrm{~mm}$ in length, $68 \mathrm{~mm}$ in height, and 16 or $32 \mathrm{~mm}$ in width. We can find four strain gauges on each force meter - two on one side $30 \mathrm{~mm}$ from the edge of the force meter and two on the other side $60 \mathrm{~mm}$ from the edge of the force meter. These allow us to measure the deformation along its full length.

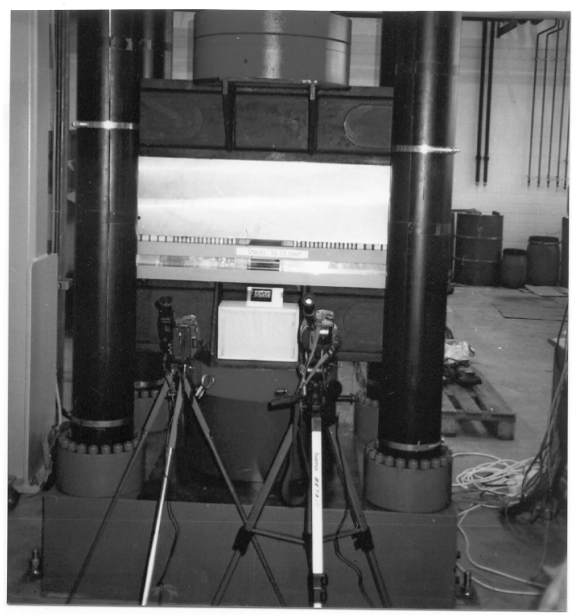

Figure 2: $\quad$ Testing device. Two camcorders recorded the test.

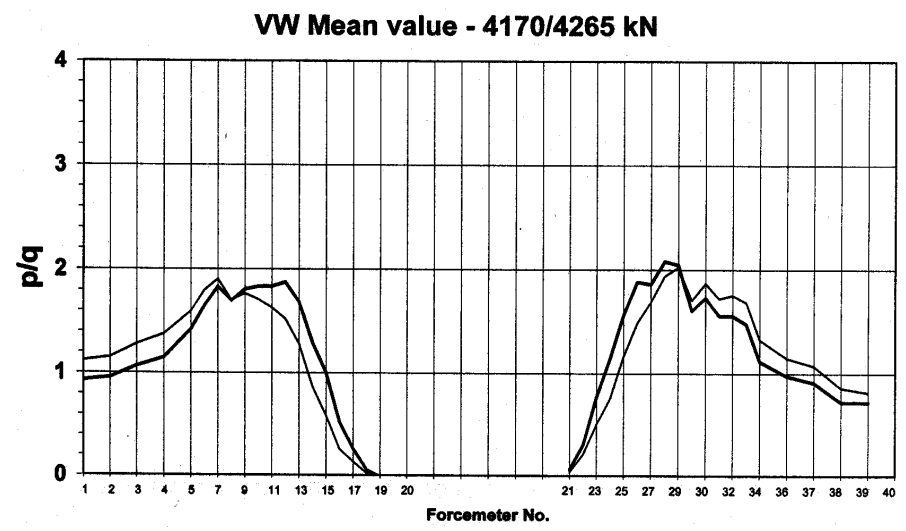

Figure 3: Mean stress distribution of coal seam loading before (thick line) and after a bump. The force is $4170-4265$. 
Dates of every force meter were read automatically by a Brüel and Kjaer strain gauge bridge every 10 seconds and deposited in a computer. A reading of 40 force meters takes $1,2 \mathrm{~s}$.

\subsection{Some of the results}

More results are in [4-6].

VW 21



Figure 4: Loading of the coal seam during test VW 21 in axonometry. On axis $\mathrm{x}$ is the force meter number, on axis $\mathrm{y}$ is the time from the start of the test, and on the vertical axis is stress that acts in each force meter in corresponding time.



Figure 5: $\quad$ Loading cell. Right with sample and force meters. 




Figure 6: $\quad$ State before bump.

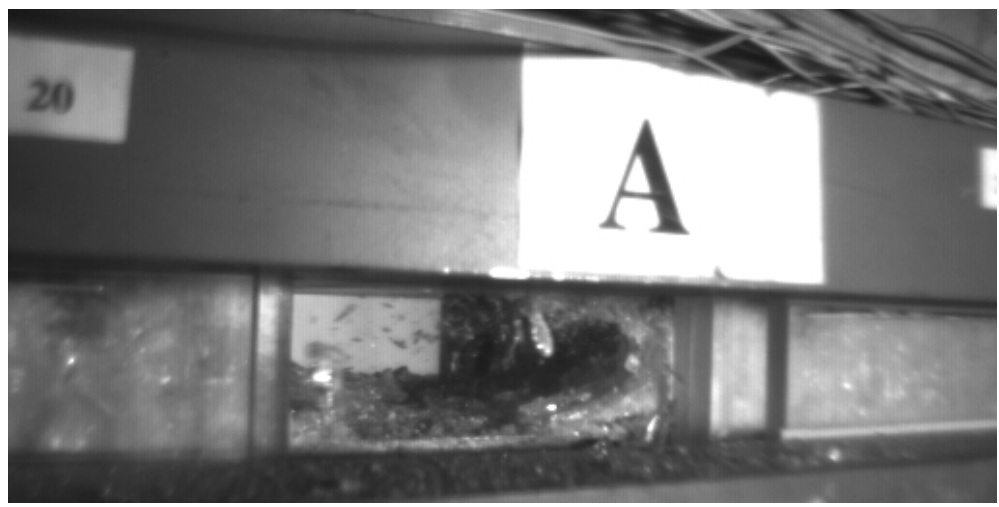

Figure 7: $\quad$ First extrudes appears.

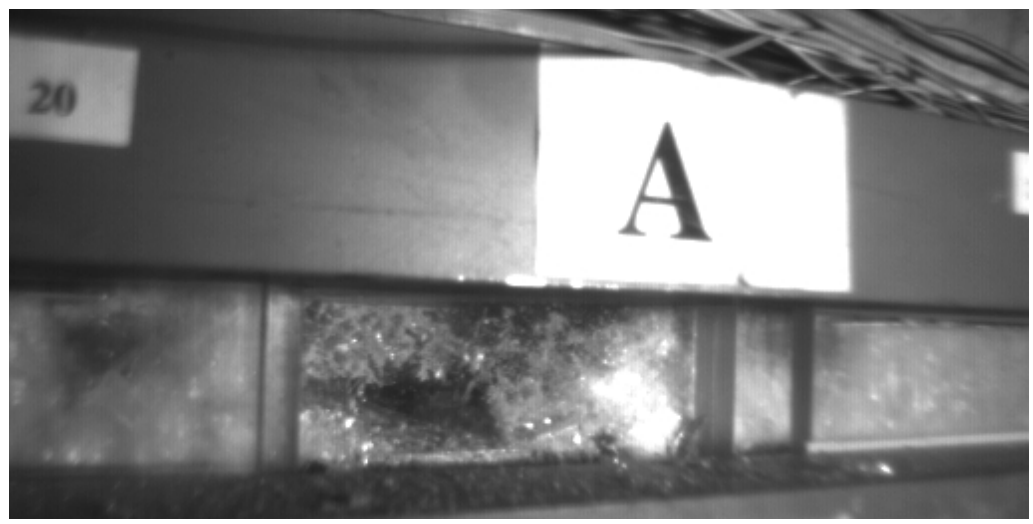

Figure 8: $\quad$ Early stage of bump. 


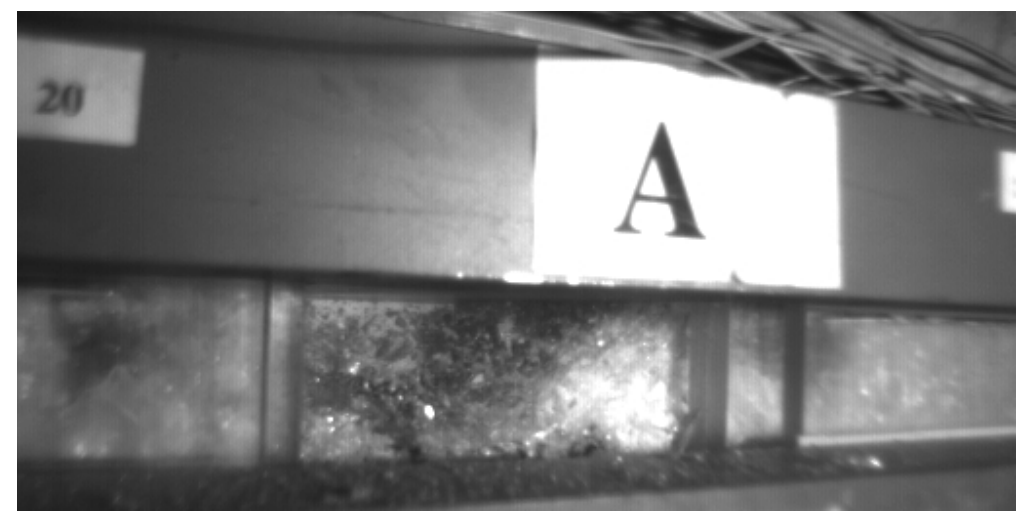

Figure 9: Late stage of bump.

\subsubsection{Mechanics of bumps}

The last experiments were also recorded with a high-speed camera. It made it possible to watch bumps as a several second events. Figures 6-9 were chosen from continuous records. It follows from them that the studied bump started (similar to an earthquake) with a small extrude of rock mass, see Figure 6, followed by the main bump, Figures 7 and 8 , and the state after the bump ended, Figure 9. The event sometimes ends with small extrudes of rock, but not in the described case. Video from the described case will be part of presentation.

\subsubsection{Some facts, that follows from tests}

- Extrude rock mass is located on the only narrow strip next to the free rock surface. This breadth was only $15-40 \%$ of the height of the coal seam and was proportionate to the bump force. The bigger the bump was, the broader the amount of extruded rock. The height of the coal seam was $70 \mathrm{~mm}$ in the experiment; the bump extruded from approximately 10 to $30 \mathrm{~mm}$ of rock. After the bump the surface of the coal was not smooth, it was uneven.

- In one case (one from about 30 cases) the bump came in two waves.

- Bumps in experimental conditions last about $20 \mathrm{~ms}$, (a two waves bump lasts $50 \mathrm{~ms}$ ) and the whole event lasts about $0,5 \mathrm{~s}$.

- The time between the first extrusion and the bump was 20-200 ms.

\section{Mathematical model}

$P_{F C}{ }^{2 D}$ (Particle Flow Code in Two Dimensions) developed by Itasca, USA was used for the numerical modelling part of the project. A physical problem concerning the movement and interaction of circular particles may be modelled directly by $P F C^{2 D}$. $P F C^{2 D}$ models the movement and interaction of circular particles by the distinct element method (DEM), as described by Cundall and Strack (1979).

By bonding two or more particles together, the particles of arbitrary shape can be created: These groups of particles act as autonomous objects, provided that 
their bond strength is high. As a limiting case, each particle may be bonded to its neighbour. The resulting assembly can be regarded as a "solid" that has elastic properties and is capable of "fracturing" when the bonds break in a progressive manner. $P F C^{2 D}$ contains extensive logic to facilitate the modelling of solids as close-packed assemblies of bonded particles; the solid may be homogeneous, or it may be divided into a number of discrete regions of blocks.

The calculation method is a time stepping, explicit scheme. Modelling with $P F C^{2 D}$ involves the execution of many thousands of time steps. At each step, Newton's second law (force $=$ mass $\mathrm{x}$ acceleration) is integrated twice for each particle to provide updated velocities and new positions, given a set of contact forces acting on the particle. Based on these new particle positions, contact forces are derived from the relative displacements for pairs of particles: a linear or non-linear force/displacement law at contacts may be used.

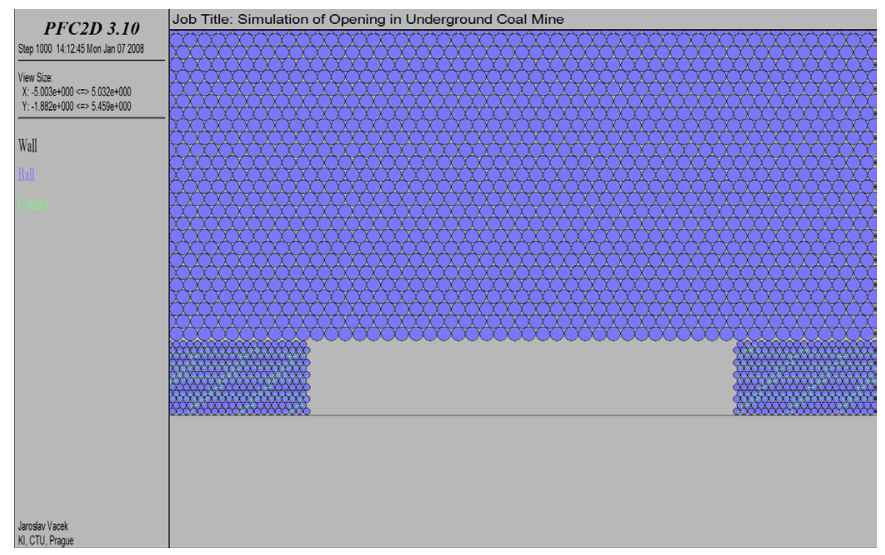

Figure 10: Mathematical model before a bump.

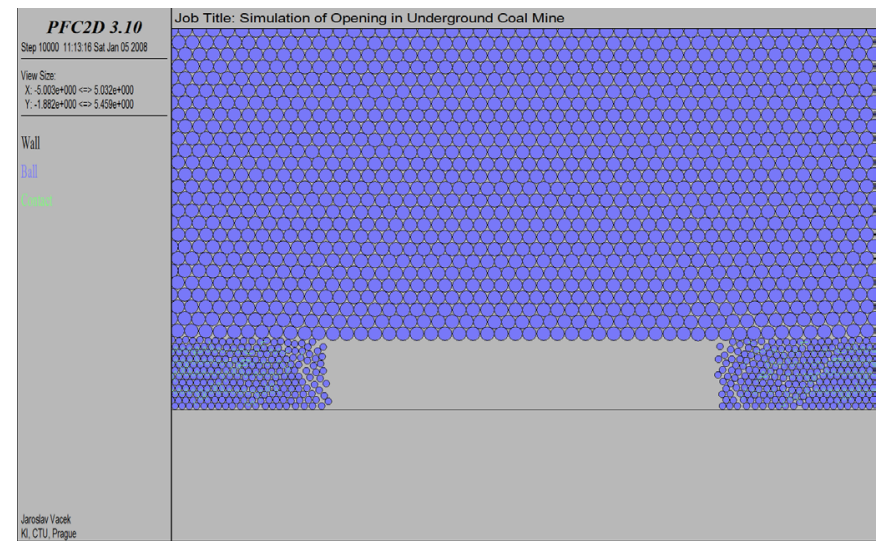

Figure 11: The first stage of a bump. 
166 Underground Spaces I

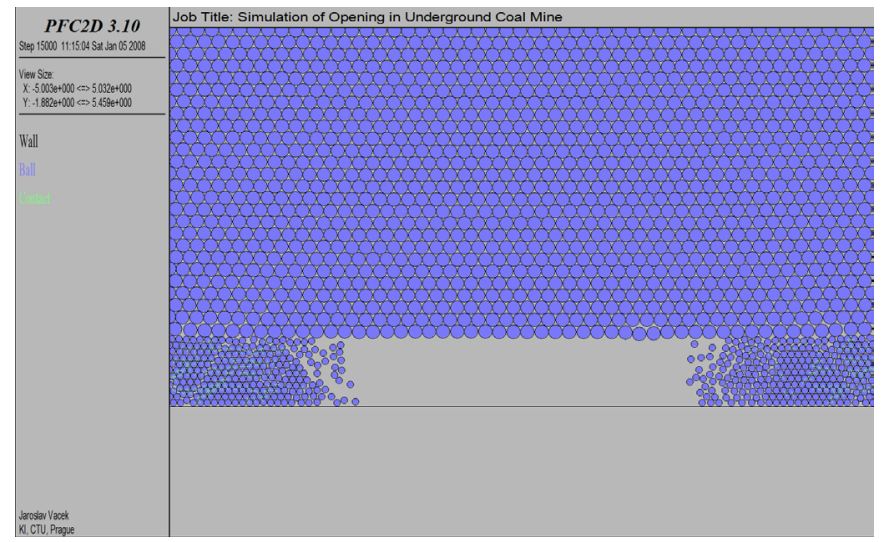

Figure 12: Next stages of a bump.



Figure 13: Next stages of a bump.

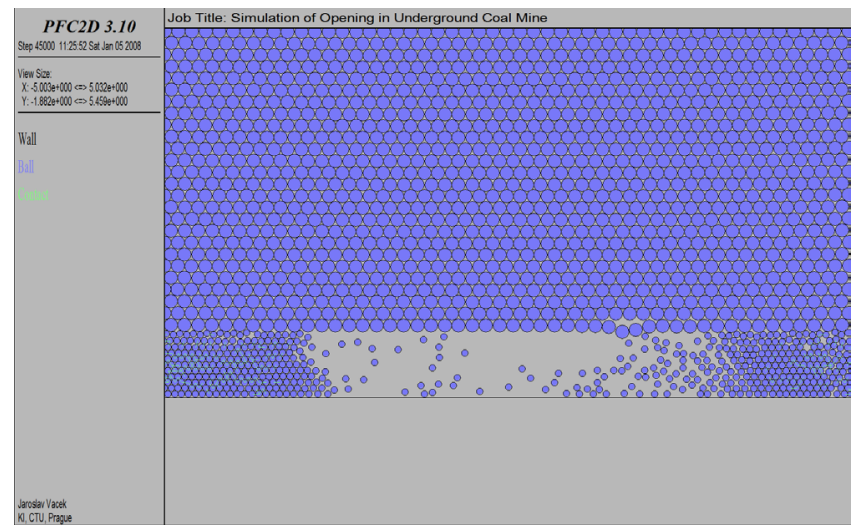

Figure 14: Late stage of a bump.

WIT Transactions on the Built Environment, Vol 102, (C) 2008 WIT Press www.witpress.com, ISSN 1743-3509 (on-line) 
Figs. 10-14 show details of the mathematical model of the bump and Figure 15 shows the typical stress distribution along the coal mine. The stress grows (I, II) until the first bump initiation (III). This occurs at the $5^{\text {th }}$ measurement cycle approximately, then the stress decreases in this location, but it increases simultaneously at the $7^{\text {th }}$ measurement cycle, when the second bump initiation occurs (IV). The subsequent bump initiations can be expected in the $8^{\text {th }}$ and $10^{\text {th }}$ measurement cycles (V, VI).

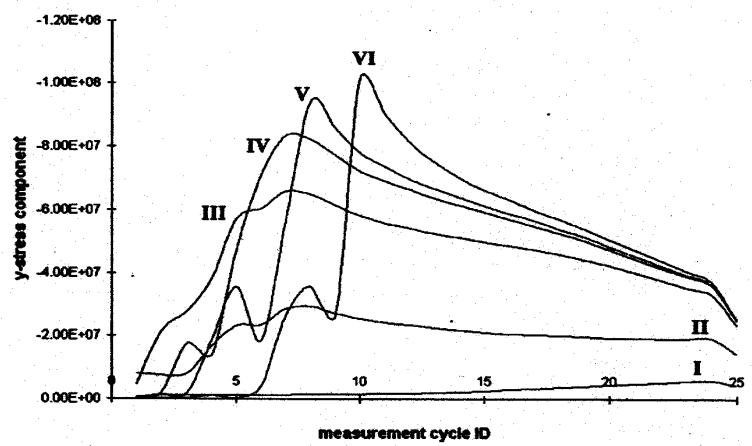

Figure 15: Stress distribution along the coal mine (left side) I - 5000 cycles, II7000 cycles, III - 9000 cycles, IV - 12000 cycles, V - 15000 cycles, VI - 26000 cycles (number of time steps, iterations).

\section{Conclusion}

A combination of experimental and mathematical models appears very appropriate for a study of the stress distribution in a coal seam before and after bump initiation. Both methods enable a time dependent study of the problem and enable study of the development of cracks during bump initiation, and then extrusion of material into an open space during a bump. Thus they offer a description of the problem that is very close to reality.

\section{Acknowledgement}

This research and this paper have been sponsored by the Grant Agency of Czech Republic, (GAČR), grant number 103 / 08 / 0922 "Influence of shocks and impacts loading on structures".

\section{References}

[1] Foss, M., M., Westman, E., C.: Seismic Method for in-seam coal mine ground control problems, SEG International Exposition and $64^{\text {th }}$ Annual Meeting, Los Angeles, 1994, p 547-549 
[2] Goodman, R. E.: Introduction to Rock Mechanics, John Wiley \& sons, 1989, $562 \mathrm{p}$.

[3] Torańo, J., Rodríguez, R., Cuesta, A.: Using experimental measurements in elaboration and calibration of numerical models in geomechanics, Computation Methods and Experimental Measurements X, Alicante, 2001, p. $457-476$

[4] Vacek, J., Procházka, P.: Rock bumps occurrence during mining, Computation Methods and Experimental Measurements X, Alicante, 2001, p. $437-446$

[5] Vacek J., Bouška, P.: Stress distribution in coal seam before and after bump initiation, Geotechnika 2000, Glivice- Ustroň 2000, p. 55-66

[6] Vacek, J., Procházka, P.: Behaviour of brittle rock in extreme depth, 25th Conference on Our World in Concrete \& Structures, Singapore, 2000, p. 653-660

[7] Williams, E. M., Westman, E. C.: Stability and Stress Evaluation in Mines Using In-Seam Seismic Methods, $13^{\text {th }}$ Conference on ground control in mining, US Bureau of Mines, 1994, p. 290-297 